Original Article

\title{
FORMULATION OF SOLID DOSAGE FORM CONTAINING CLOPIDOGREL AND CILOSTAZOL AND ITS HPLC ANALYSIS
}

\author{
ASHA THOMAS, SURAJ BHOSALE, RABINDRA NANDA \\ Department of Pharmaceutical Chemistry, Dr. D. Y. Patil Institute of Pharmaceutical Sciences and Research, Pimpri, Pune 411018, \\ Maharashtra \\ Email: dypharmachem@yahoo.co.in
}

Received: 09 Jul 2016 Revised and Accepted: 20 Apr 2017

\section{ABSTRAC'T}

Objective: The verify now P2Y12 assay suggested that addition of cilostazol to clopidogrel proves to be efficious in the treatment of patients with cardiovascular disease (CVD). Based on these findings, an attempt has been made to formulate solid dosage form containing the two drugs at the recommended concentrations and develop and validate reverse phase high-performance liquid chromatography (HPLC) method for their simultaneous estimation.

Methods: A combined tablet dosage form containing cilostazol (100 mg) and clopidogrel (75 mg) was formulated by direct compression method. A reverse phase HPLC method using C8 column, employing 0.025M phosphate buffer: methanol: acetonitrile (20:40:40\% v/v) as mobile phase at a flow rate of 1 $\mathrm{ml} / \mathrm{min}$ with ultraviolet (UV) detection at $237 \mathrm{~nm}$ was developed and validated as per International Council on Harmonisation (ICH) guidelines.

Results: The prepared powder blend showed excellent flow properties and formulated tablet passed the standard tests for tablets. The tablets were suitably analyzed by the reverse phase HPLC method with a retention time (RT) of 3.82 and 7.72 min for cilostazol and clopidogrel respectively. The method exhibited linearity $\left(10-100 \mu \mathrm{g} / \mathrm{ml}\right.$ for cilostazol and $7.5-75 \mu \mathrm{g} / \mathrm{ml}$ for clopidogrel) with $\mathrm{r}^{2}=0.999$ for both drugs respectively. The recoveries of cilostazol and clopidogrel were $98.97 \%$ and $98.94 \%$ respectively. The relative standard deviation (RSD) was $<2 \%$ indicating good method precision. The stability indicating properties evaluated by forced degradation studies showed good separation of the drugs from their degradation products.

Conclusion: A simple, precise, robust, stability-indicating HPLC method was developed for simultaneous assay of cilostazol and clopidogrel in prepared tablet formulation and validated as per ICH guidelines. This method can be employed for the analysis and stability studies of solid dosage forms containing the two drugs.

Keywords: Cilostazol, Clopidogrel, HPLC, Validation

(C) 2017 The Authors. Published by Innovare Academic Sciences Pvt Ltd. This is an open access article under the CC BY license (http://creativecommons.org/licenses/by/4.0/) DOI: http://dx.doi.org/10.22159/ijpps.2017v9i6.13987

\section{INTRODUCTION}

Cilostazol, chemically, 6-[4-1(-cyclohexyl-1H-tetrazol-5yl-butoxyl 3-4 dihydro (1H)-quinoline $2(1 \mathrm{H})$-one (fig. 1 ) is a calcium channel blocker and is official in Indian Pharmacopoeia (IP), British Pharmacopoeia (BP) and United State Pharmacopoeia (USP) [1-3]. Clopidogrel chemically, (+)-(s)- $\alpha$-(2-chlorophenyl)-6,7 dihydrothieno[3, 2-c] pyridine- $5(4 \mathrm{H})$-acetic acid methyl ester sulphate (fig. 1) is a potent oral antiplatelet agent often used in coronary artery disease, peripheral vascular disease and cardiovascular diseases and is official in BP and USP.

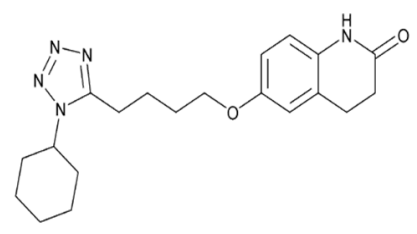

\section{(A)}

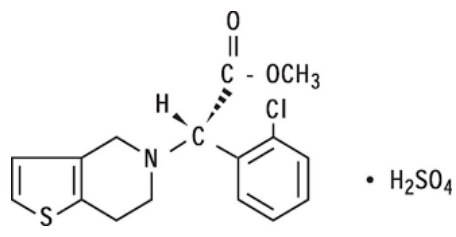

(B)

Fig. 1: Structure of (A) cilostazol and (B) clopidogrel
Clopidogrel and cilostazol are used separately in the treatment of various cardiovascular diseases. Literature reports suggest that the inhibitory response to clopidogrel differs to a large extent among individuals receiving the therapy. Also, resistance to clopidogrel is a major risk factor for thrombotic events in patients with cardiovascular disease conditions. In a study carried out by Maruyama H. et al., evaluated by the VerifyNow P2Y12 assay, the effect of the addition of cilostazol on clopidogrel resistance was investigated [4]. Of the 72 patients in the study, 15 patients who received $75 \mathrm{mg}$ of clopidogrel in addition to $100 / 200 \mathrm{mg}$ of cilostazol, platelet inhibition was intensified; thereby suggesting that the addition of cilostazol may proves to be efficious in the treatment of patients with ischemic stroke and other CVD. Based on these findings, in the present study attempts have been made to formulate solid dosage form containing the two drugs at the recommended concentrations and develop and validate a suitable chromatographic method for their simultaneous estimation.

Literature survey reveals several spectrophotometric and chromatographic [5-18] methods for the estimation of cilostazol and clopidogrel alone and in combination with other drugs. However, no HPLC method has been reported for the simultaneous determination of cilostazol and clopidogrel in combination dosage form. This paper describes a rapid, accurate, economical and validated HPLC method for the simultaneous quantification of these compounds in bulk and solid dosage form. The proposed method is optimized and validated as per the International Council on Harmonization (ICH) guidelines.

\section{MATERIALS AND METHODS}

Chemicals and reagents

All the chemicals and reagents used in the study were of analytical 
grade. Cilostazol was obtained as gift sample from Amsal Chem. Pvt. Ltd., Mumbai, India and clopidogrel were obtained from Aarti Drugs Ltd., Mumbai, India. The combined tablet dosage form was formulated in the house.

\section{Instruments used}

The HPLC instrument used was a binary gradient Agilent 1120 system equipped with high-pressure double head reciprocating pumps with a discharge rate of 0.001 to $9.999 \mathrm{ml} / \mathrm{min}$ at a maximum operating pressure of $41.2 \mathrm{MPa}$ with a pressure display accuracy of $\pm 5 \%$. Up to 2 mobile phases with a variable mixing ratio range of 0 to $100 \%$ (in increments of $1 \%$ ) can be used. The instrument was equipped with a variable wavelength UV detector $(190-800 \mathrm{~nm})$ fitted with a deuterium lamp. The sample injection was carried out using a manual Rhenodyne sample injector with a fixed volume sample loop (20ul). The data was recorded using Ez-Chrome Elite software. Analytical balance (Shimadzu/AX200, Japan), mini punch tablet machine (Rimek mini press-1, Karnavati Engineering Ltd., Gujarat, India), digital vernier calliper (Mitutoyo/CD-6 CS), fourier transform infrared spectrophotometer (FTIR) (Shimadzu/8400s, Japan), Roche type friability testing apparatus (Lab Hosp Instrument and Manufacturing Co., Mumbai, India), digital programmable melting point apparatus (VMP-PM, Veego Instruments Corporation, Mumbai, India), six station USP disintegration testing apparatus (DT60, Veego Scientific Instruments, Mumbai), hardness tester (Monsanto), sonicater (Wensar, 2.5. l), pH meter (EQ614A, EQUIP Tronics Instruments, Mumbai, India) were employed in the study.

\section{Preparation of stock and working standards}

Accurately weighed quantities, $10 \mathrm{mg}$ cilostazol and $7.5 \mathrm{mg}$ clopidogrel were transferred to separate $100.0 \mathrm{ml}$ volumetric flask, dissolved and diluted up to the mark with mobile phase. From the above solution, $4.0 \mathrm{ml}$ was diluted to $10.0 \mathrm{ml}$ with mobile phase to obtain working standards of concentration $40 \mu \mathrm{g} / \mathrm{ml}$ of cilostazol and $30 \mu \mathrm{g} / \mathrm{ml}$ of clopidogrel. The solutions were filtered through $0.22 \mu$ membrane filter. $20 \mu \mathrm{l}$ solution was injected each time into the column for five times, and the corresponding chromatograms were recorded. From these chromatograms, the retention times and areas under the peaks of drugs were noted.

\section{Selection of mobile phase and optimization of chromatographic conditions}

A standard working solution of cilostazol $(10 \mu \mathrm{g} / \mathrm{ml})$ and clopidogrel $(7.5 \mu \mathrm{g} / \mathrm{ml})$ were prepared and suitably diluted with mobile phase. The standard solutions were filtered through $0.22 \mu$ membrane filter. The filtrates were injected into the HPLC system and run in different solvent systems. Mixtures of different solvents were tried to determine the optimum chromatographic conditions for effective separation of clopidogrel and cilostazol. After several trials, it was found that the mixture of $0.025 \mathrm{M}$ phosphate buffer: acetonitrile: methanol $(20: 40: 40 \mathrm{v} / \mathrm{v} / \mathrm{v})$ gives satisfactory results as compared to other mobile phases. Finally, the optimal composition of the mobile phase, $0.025 \mathrm{M}$ phosphate buffer: acetonitrile: methanol (20:40:40 $\mathrm{v} / \mathrm{v} / \mathrm{v}$ ), at a flow rate of $1.0 \mathrm{ml} / \mathrm{min}$ showed good peak shape, resolution and desired elution time. RT of cilostazol was $3.82 \mathrm{~min}$ and that of clopidogrel was $7.72 \mathrm{~min}$ under the optimized conditions employed for the analysis. The $\mathrm{pH}$ of phosphate buffer was set to 3.2, adjusted with orthophosphoric acid $(10 \% \mathrm{v} / \mathrm{v})$. The chromatographic separation was achieved on a reverse phase Kromasil C8 column $(250 \times 4.6 \mathrm{~mm}, 5 \mu)$ at ambient temperature with UV detection at $237 \mathrm{~nm}$. The mobile phase was suitably sonicated and vacuum filtered through a $0.45 \mu$ membrane filter prior to analysis.

\section{Formulation of tablets containing cilostazol and clopidogrel}

As there is no formulation currently available in the market containing cilostazol and clopidogrel in combination, attempts were made to formulate combined solid dosage form containing the two drugs by direct compression method. Tablet dosage form containing cilostazol (100 mg) and clopidogrel (75 mg) were formulated using $8 \mathrm{~mm}$ concave punches on rotary tablet compression machine using microcrystalline cellulose, magnesium stearate, croscarmellose sodium and talc as excipients. The powder blends prepared were initially studied for their flow properties by measuring the angle of repose, bulk density, tapped density, Carr's compressibility index and Hausner ratio which were within the permissible limits indicating good flow properties. The prepared tablets were also evaluated for their weight variation, hardness and friability as per standard procedures (table 1).

Table 1: Evaluation of combined tablet formulation

\begin{tabular}{llll}
\hline Parameters & Standard values & Observed value & Inference \\
\hline Bulk Density & Less than 1 & 0.44 & Excellent flow properties \\
Tapped Density & Less than 1 & 0.46 & Excellent flow properties \\
Hausner ratio & Less than 1.25 & 1.11 & Good flow properties \\
Carr's compressibility index & $5-15$ & $7.12 \%$ & Excellent flow properties \\
Weight variation & Less than 7.5 & $4.5 \%$ & Passes \\
Friability & Less than 1 & $0.5 \%$ & Passes \\
Hardness & $3-6 \mathrm{~kg} / \mathrm{cm}^{2}$ & $3-4 \mathrm{~kg} / \mathrm{cm}^{2}$ & Passes \\
Disintegration time & $<30 \mathrm{~min}$ & $1.23 \mathrm{~min}$ & Passes \\
\hline
\end{tabular}

\section{Assay of tablet formulation}

Twenty tablets were accurately weighed and powdered, an amount equivalent to $7.5 \mathrm{mg}$ of clopidogrel and $10 \mathrm{mg}$ of cilostazol was weighed, transferred to a $100.0 \mathrm{ml}$ volumetric flask, $25 \mathrm{ml}$ mobile phase $(0.025 \mathrm{M}$ phosphate buffer, $\mathrm{pH}$ set to 3.2 with orthophosphoric acid (10\% v/v): acetonitrile: methanol 20:40:40 $\mathrm{v} / \mathrm{v} / \mathrm{v}$ ) was added and ultrasonicated for $15 \mathrm{~min}$. Volume was then made up to the mark with mobile phase. The solution was mixed and filtered through a $0.22 \mu$ membrane filter. From the filtrate, $4 \mathrm{ml}$ solution was diluted to $10.0 \mathrm{ml}$ with mobile phase to obtain working solutions of concentration $30 \mu \mathrm{g} / \mathrm{ml}$ of clopidogrel and $40 \mu \mathrm{g} / \mathrm{ml}$ of cilostazol. The sample solutions $(20 \mu \mathrm{l})$ were injected into the column under optimized chromatographic conditions. Each solution was injected in triplicate. The corresponding chromatograms were recorded and area of each peak was measured at $237 \mathrm{~nm}$.

\section{Validation of HPLC method [19-21]}

The objective of method validation is to demonstrate that the method is suitable for its intended purpose. The proposed HPLC method for estimation of cilostazol and clopidogrel were validated as per ICH guidelines, Q2A and Q2B.

\section{System suitability tests}

The system suitability parameters (tailing factor, resolution, column efficiency (number of theoretical plates, $\mathrm{N}$ ) and system precision were studied. System suitability tests were carried out to ensure that the optimized chromatographic conditions (HPLC instrument, reagents, solvents, column) are suitable for the analysis of cilostazol and clopidogrel. Accordingly, mixed standard solutions containing cilostazol $(10 \mu \mathrm{g} / \mathrm{ml})$ and clopidogrel $(7.5 \mu \mathrm{g} / \mathrm{ml})$ were prepared and used for analysis. Six replicate injections of standard solutions were injected into the column under the optimized chromatographic conditions. Typical chromatograms were obtained and system suitability parameters were computed.

\section{Solution stability}

Stability of drugs in the mobile phase was checked by storing the test solutions in tightly capped vials at room temperature for three 
days. The solutions were then analysed using the proposed HPLC method.

\section{Linearity and range}

From the standard stock solutions; 1.0, 2.0, 3.0, 4.0, 5.0 and $6.0 \mathrm{ml}$ were transferred to separate $10.0 \mathrm{ml}$ volumetric flask and diluted up to the mark with mobile phase. Standard solutions in the concentration range of $10-100 \mu \mathrm{g} / \mathrm{ml}$ for cilostazol and $7.5-75 \mu \mathrm{g} / \mathrm{ml}$ for clopidogrel were obtained. The diluted solutions were filtered through $0.2 \mu$ membrane filter. Then each solution $(20 \mu \mathrm{l})$ was injected into the column using the optimized chromatographic conditions. The corresponding chromatograms were recorded and area of each peak of cilostazol and clopidogrel were measured at $237 \mathrm{~nm}$.

\section{Accuracy}

The accuracy of an analytical method expresses the nearness between the true value and the experimental value. The accuracy of the method was performed by recovery studies in which the test samples were spiked with the standard at 80,100 , and $120 \%$ of the nominal concentration $(n=3)$.

\section{Precision}

The precision of the assay was assessed with respect to repeatability and intermediate precision studies. The intermediate precision of the method (intra and inter-day precision) was studied by measuring the response of sample solutions on the same day at different time intervals and on different days.

\section{Robustness}

Robustness is an indication of the reliability of the analytical method during normal usage. The effect of various deliberate variations in chromatographic method parameters like a change in flow rate and mobile phase ratio on retention time and tailing factor were monitored. A sample solution containing $30 \mu \mathrm{g} / \mathrm{ml}$ of clopidogrel and $40 \mu \mathrm{g} / \mathrm{ml}$ of cilostazol was injected (in triplicate) into sample injector of HPLC under the varied conditions.

\section{Forced degradation study}

Forced degradation studies are undertaken to assess the capability of an analytical method to measure an active ingredient without any inference of its degradation products, thereby proving to be stability indicating. Literature study reports forced degradation studies for cilostazol and clopidogrel. Cilostazol showed significant degradation on exposure to hydrogen peroxide as the oxidising agent (oxidative degradation) [22]. In the case of clopidogrel, extensive degradation was observed under acid and base induced hydrolysis. [(S)-2-(2chlorophenyl)-2-(6,7-dihydrothieno[3,2-c] pyridine-5(4H)-ylacetic acid was the major degradation product formed under both, the acid and base induced degradation conditions [23-24]. However, both drugs were reported to be stable on exposure to light, heat and neutral hydrolysis in presence of water. Based on these finding, in the present study, forced degradation was performed under oxidative stress condition for cilostazol and acid and base induced hydrolysis for clopidogrel.

\section{Peroxide degradation sample of cilostazol}

Accurately weighed quantity ( $10 \mathrm{mg}$ ) of cilostazol was transferred to a $100 \mathrm{ml}$ volumetric flask. To it, $20 \% \mathrm{H}_{2} \mathrm{O}_{2}(5 \mathrm{ml})$ was added, heated on a water bath at $80^{\circ} \mathrm{C}$ for $3 \mathrm{~h}$. The solution was then cooled and volume made up to the mark with mobile phase. From the above solution, a suitable aliquot $(4.0 \mathrm{ml})$ was diluted to $10.0 \mathrm{ml}$ with mobile phase (conc. $40 \mu \mathrm{g} / \mathrm{ml}$ ). The resultant solution was filtered through a $0.22 \mu$ membrane filter. The prepared solution $(20 \mu \mathrm{l})$ was injected into the reverse phase C8 column and the chromatogram was obtained.

\section{Acid/Base degradation sample of clopidogrel}

Accurately weighed quantities of clopidogrel $(7.5 \mathrm{mg}$ each) were transferred to separate $100 \mathrm{ml}$ volumetric flasks. To it, $5 \mathrm{~N} \mathrm{HCl} \mathrm{(5} \mathrm{ml)}$ for acid hydrolysis and $0.1 \mathrm{~N} \mathrm{NaOH}(5 \mathrm{ml})$ for alkali hydrolysis was added, heated on a water bath at $80^{\circ} \mathrm{C}$ for $3 \mathrm{~h}$. The solutions were then cooled, neutralized with $5 \mathrm{~N} \mathrm{NaOH}$ and $0.1 \mathrm{~N} \mathrm{HCl}$ for acid and base degraded samples respectively. The volume was then made up to the mark with mobile phase. From the above solutions, suitable aliquots $(4.0 \mathrm{ml})$ were diluted to $10.0 \mathrm{ml}$ with mobile phase (conc. $30 \mu \mathrm{g} / \mathrm{ml}$ respectively). The solutions were then filtered through $0.22 \mu$ membrane filter. The prepared solutions $(20 \mu \mathrm{l})$ were injected into the C8 column and the chromatograms were obtained.

\section{RESULTS AND DISCUSSION}

\section{System suitability tests}

The system suitability parameters including theoretical plate, tailing factor and resolution met the compendium acceptance limits (table 2).

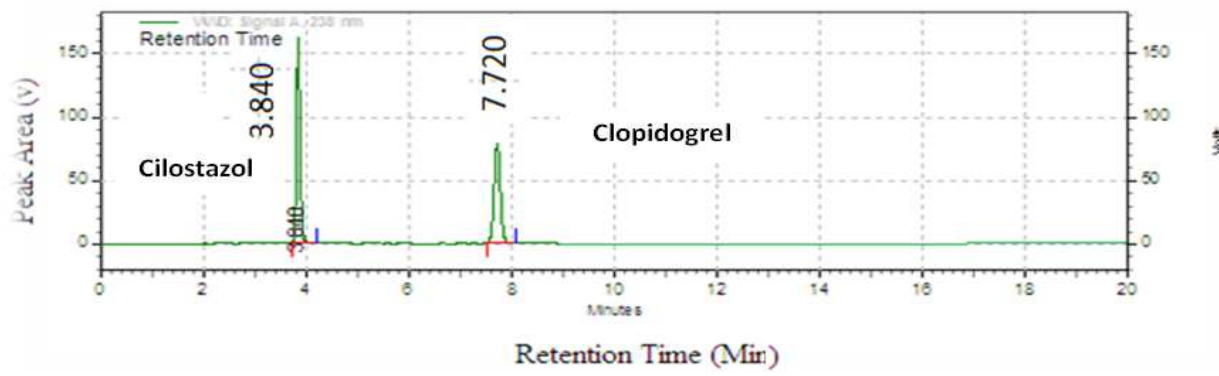

(A)

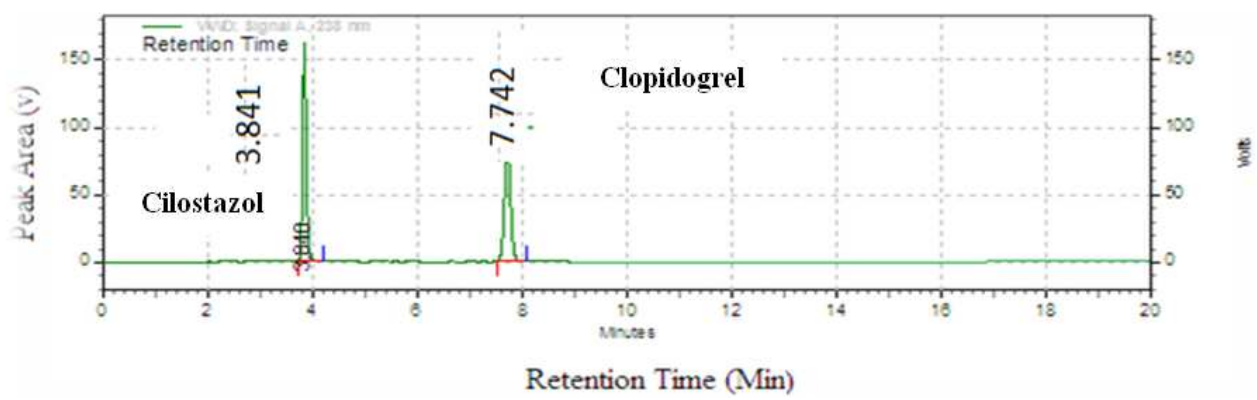

(B)

Fig. 2: Chromatogram of (A) standard and (B) tablet sample containing cilostazol and clopidogrel by HPLC 
Table 2: System suitability parameters for cilostazol and clopidogrel

\begin{tabular}{lll}
\hline Parameter & Standard values & Observed values \\
\cline { 3 - 3 } & & Cilostazol \\
\hline Tailing factor & NMT 2 & 1.1013 \\
Theoretical plates & NLT 2000 & 13738 \\
Resolution & NLT 2 & 14.23 \\
\hline
\end{tabular}

NMT-Not more than NLT-Not less than

\section{Assay of tablet formulation}

The chromatogram for the tablet sample showed two peaks with RT of 3.841 and $7.742 \mathrm{~min}$ for cilostazol and clopidogrel respectively indicating that there is no interference of the excipients present in the tablet formulation.

The results are presented in table 3 and fig. 2 respectively.

Table 3: Assay of tablet formulation containing cilostazol and clopidogrel

\begin{tabular}{llllll}
\hline S. No. & Drugs & Amount of drug estimated (mg/tab) & \% label claim (n=6) & SD(n=6) & \%RSD (n=6) \\
\hline 1 & Cilostazol & 9.99 & 98.70 & 0.51 \\
2 & Clopidogrel & 7.49 & 99.92 & 0.522 \\
\hline
\end{tabular}

SD: Standard deviation; RSD: Relative standard deviation

\section{Solution stability}

The solutions were analyzed by HPLC on three consecutive days (table 4). The stability analysis indicated that the drugs were stable in the selected mobile phase for a period of up to $72 \mathrm{~h}$ of the study.

\section{Linearity}

Each sample solution was injected in triplicate and the mean peak areas for cilostazol and clopidogrel were calculated. The standard calibration curves of peak area verses concentration were plotted; the coefficient of correlation, slope and intercept values were recorded for clopidogrel and cilostazol respectively. According to USP, correlation coefficient $\left(\mathrm{r}^{2}\right)$ for calibration curve must be $>0.995$; the correlation coefficients were found to be 0.999 for both drugs indicating good linearity of calibration curves. The linearity is as shown in fig. 3.

\section{Accuracy}

For cilostazol, \% recovery was found to be $100.61,98.97,101.16 \%$ and $100.20,98.94,101.15 \%$ for clopidogrel at $80,100,120 \%$ of the test concentrations (table 5). All recovery samples were within the acceptable range (\% recovery: $97.0-103.0 \%$ ).

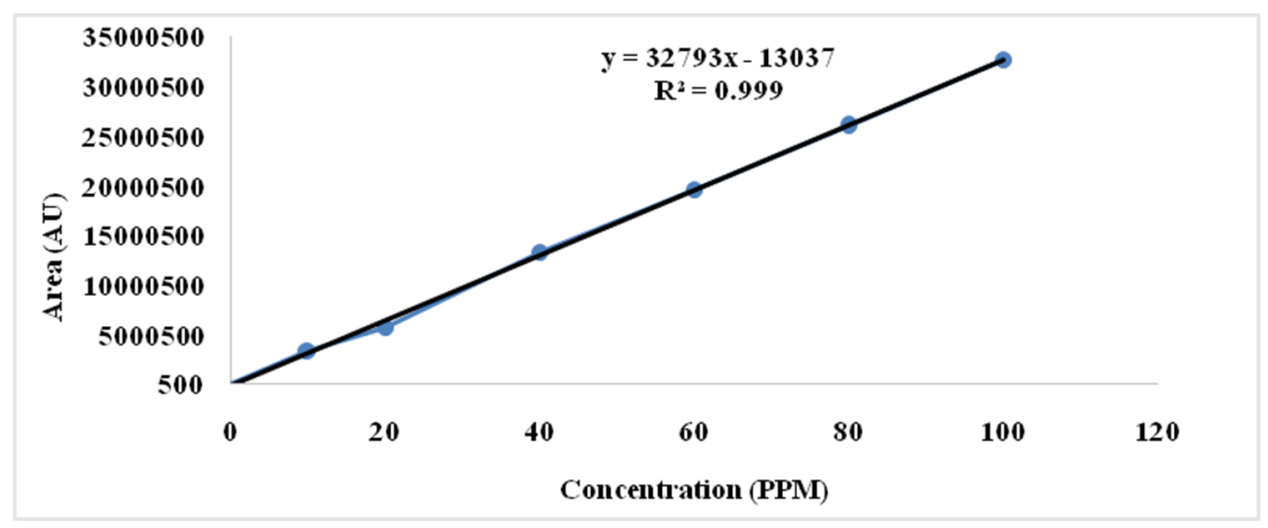

(A)

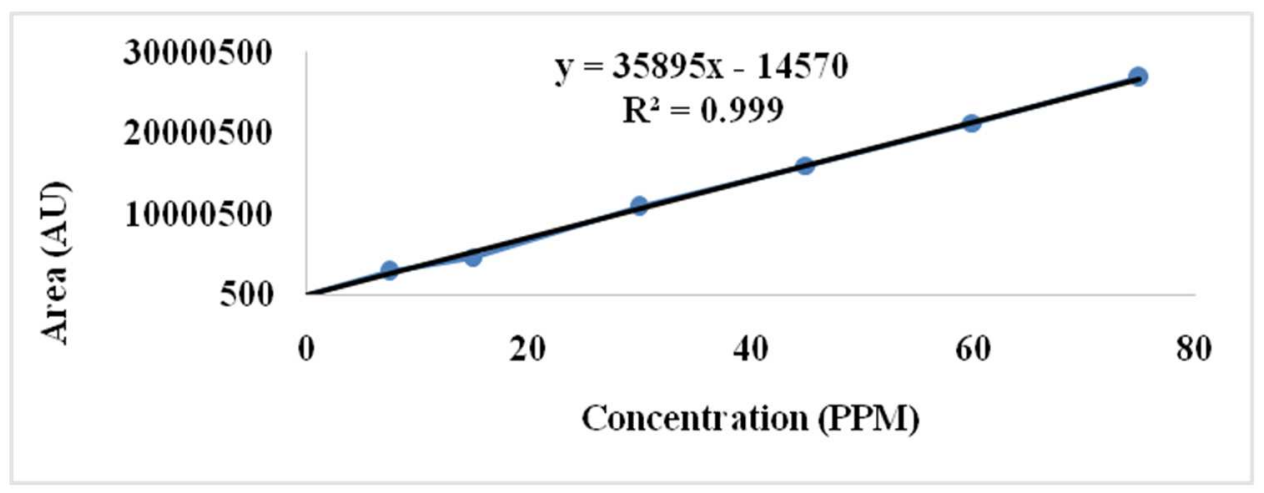

(B)

Fig. 3: Standard calibration curve for (A) cilostazol and (B) clopidogrel by HPLC 
Table 4: Solution stability for cilostazol and clopidogrel

\begin{tabular}{|c|c|c|c|c|}
\hline \multirow[t]{2}{*}{ Day } & \multicolumn{2}{|l|}{ Cilostazol } & \multicolumn{2}{|l|}{ Clopidogrel } \\
\hline & Conc $(\mu \mathrm{g} / \mathrm{ml})$ & \% assay & Conc $(\mu \mathrm{g} / \mathrm{ml})$ & \% Assay \\
\hline Day 1 & 40.00 & 99.52 & 30.00 & 100.01 \\
\hline Day 2 & 40.11 & 99.81 & 30.02 & 98.56 \\
\hline Day 3 & 40.13 & 99.86 & 30.06 & 98.26 \\
\hline Mean & 40.08 & 99.73 & 30.025 & 98.94 \\
\hline SD & 0.064 & 0.183 & 0.030 & 0.935 \\
\hline \% RSD & 0.16 & 0.190 & 0.101 & 0.945 \\
\hline
\end{tabular}

SD: Standard deviation; RSD: Relative standard deviation

Table 5: Accuracy of HPLC method for cilostazol and clopidogrel

\begin{tabular}{|c|c|c|c|c|c|c|}
\hline \multirow[t]{2}{*}{ Level of recovery } & \multicolumn{2}{|c|}{$\%$ recovery $(n=3)$} & \multicolumn{2}{|l|}{ SD $(n=3)$} & \multicolumn{2}{|c|}{$\% \operatorname{RSD}(n=3)$} \\
\hline & Cilostazol & Clopidogrel & Cilostazol & Clopidogrel & Cilostazol & Clopidogrel \\
\hline $80 \%$ & 100.61 & 100.20 & 1.015 & 0.904 & 1.004 & 0.902 \\
\hline $100 \%$ & 98.97 & 98.94 & 0.878 & 0.935 & 0.888 & 0.945 \\
\hline $120 \%$ & 101.16 & 101.15 & 0.620 & 0.744 & 0.6129 & 0.735 \\
\hline
\end{tabular}

SD: Standard deviation; RSD: Relative standard deviation

\section{Precision}

The precision was expressed as \% RSD using the formula $(\%$ RSD = $\mathrm{SD} /$ Mean $\mathrm{x} 100)$. The $\%$ RSD values found in the precision study
$(<2)$, as depicted in table 6 indicate that the proposed method provides acceptable intra and inter-day precision for cilostazol and clopidogrel in their simultaneous determination.

Table 6: Precision studies for cilostazol and clopidogrel

\begin{tabular}{|c|c|c|c|c|c|c|}
\hline \multirow[t]{2}{*}{ Drugs } & \multicolumn{3}{|c|}{ Intra-day precision $(n=6)$} & \multicolumn{3}{|c|}{ Inter-day precision $(n=6)$} \\
\hline & \% label claim & SD & \% RSD & \% label claim & SD & $\%$ RSD \\
\hline Cilostazol & 99.73 & 0.1895 & 0.1900 & 100.23 & 0.0650 & 0.648 \\
\hline Clopidogrel & 99.55 & 0.573 & 0.575 & 99.13 & 0.565 & 0.569 \\
\hline
\end{tabular}

SD: Standard deviation; RSD: Relative standard deviation

Table 7: Robustness study for cilostazol and clopidogrel

\begin{tabular}{|c|c|c|c|c|c|}
\hline \multicolumn{6}{|c|}{ Chromatographic changes } \\
\hline \multirow{2}{*}{$\begin{array}{l}\text { Factor } \\
\text { Flow rate }(\mathrm{ml} / \mathrm{min})\end{array}$} & \multirow{2}{*}{$\begin{array}{l}\text { Level } \\
\pm 0.1 \mathrm{ml}\end{array}$} & \multicolumn{2}{|c|}{ Retention time $(n=3)$} & \multicolumn{2}{|c|}{ Tailing factor $(n=3)$} \\
\hline & & Cilostazol & Clopidogrel & Cilostazol & Clopidogrel \\
\hline 0.9 & $-0.1 \mathrm{ml}$ & 3.9 & 7.631 & 1.14 & 1.09 \\
\hline 1.0 & 0 & 3.84 & 7.671 & 1.10 & 1.09 \\
\hline \multirow[t]{4}{*}{1.1} & $+0.1 \mathrm{ml}$ & 3.85 & 7.981 & 1.12 & 1.09 \\
\hline & Mean & 3.86 & 7.761 & 1.12 & 1.09 \\
\hline & SD & 0.032 & 0.1462 & 0.02 & 0.01 \\
\hline & RSD & 0.829 & 1.883 & 1.785 & 0.917 \\
\hline \multicolumn{6}{|l|}{$\mathrm{ACN}+\mathrm{MeOH} \mathrm{v/v/v)}$} \\
\hline 18:82 & -2 & 3.621 & 7.621 & 1.14 & 1.18 \\
\hline $20: 80$ & 0 & 3.72 & 7.723 & 1.11 & 1.17 \\
\hline \multirow[t]{4}{*}{$22: 78$} & +2 & 3.751 & 7.843 & 1.12 & 1.16 \\
\hline & Mean & 3.697 & 7.729 & 1.12 & 1.17 \\
\hline & SD & 0.067 & 0.111 & 0.015 & 0.01 \\
\hline & RSD & 1.83 & 1.437 & 1.359 & 0.854 \\
\hline
\end{tabular}

SD: Standard deviation; RSD: Relative standard deviation

\section{Robustness}

The result of the robustness study (table 7) indicated that the method was not affected by small variations in organic: aqueous composition ratio and flow rate of mobile phase and is robust.

\section{Forced degradation study}

In the forced degradation study, cilostazol on treatment with $20 \%$ $\mathrm{H}_{2} \mathrm{O}_{2}$ solution exhibited $27.88 \%$ degradation with the appearance of the degradation product peak at RT 2.69 min which was well resolved from the standard peak at RT $3.92 \mathrm{~min}$ (fig. 4). In the acid and base induced hydrolysis study of clopidogrel, achieved on treatment with $5 \mathrm{~N} \mathrm{HCl}$ and $0.1 \mathrm{~N} \mathrm{NaOH}$ respectively, clopidogrel showed $28.57 \%$ and $25.30 \%$ degradation with the appearance of degradation product peaks at RT $3.017 \mathrm{~min}$ and $2.99 \mathrm{~min}$ respectively (fig. 5 and fig. 6). Both the degradation peaks were well resolved from the standard peak at RT $7.6 \mathrm{~min}$. The tablet sample on exposure to these degradation conditions did not show any additional peaks indicating that it is stable and has not undergone degradation. 


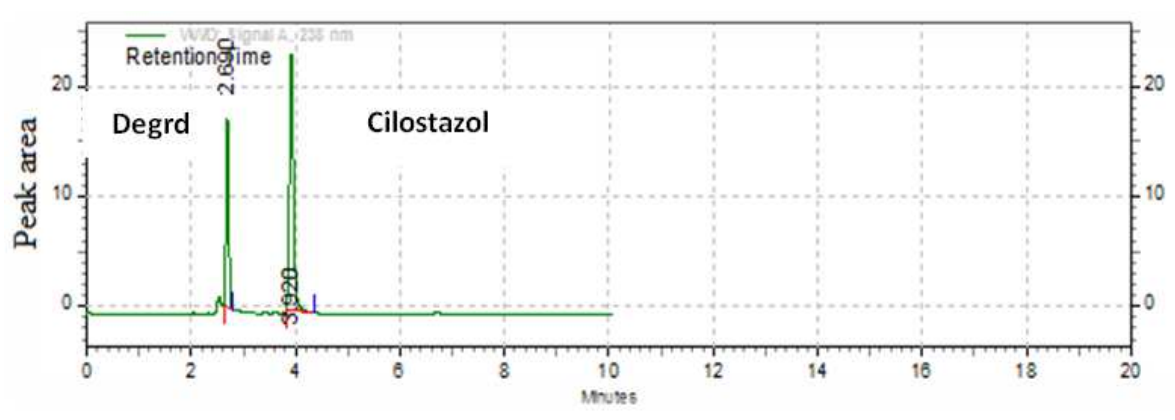

Degrd: degradation product peak at RT 2.690

Fig. 4: Chromatogram of hydrogen peroxide-induced oxidation of cilostazol

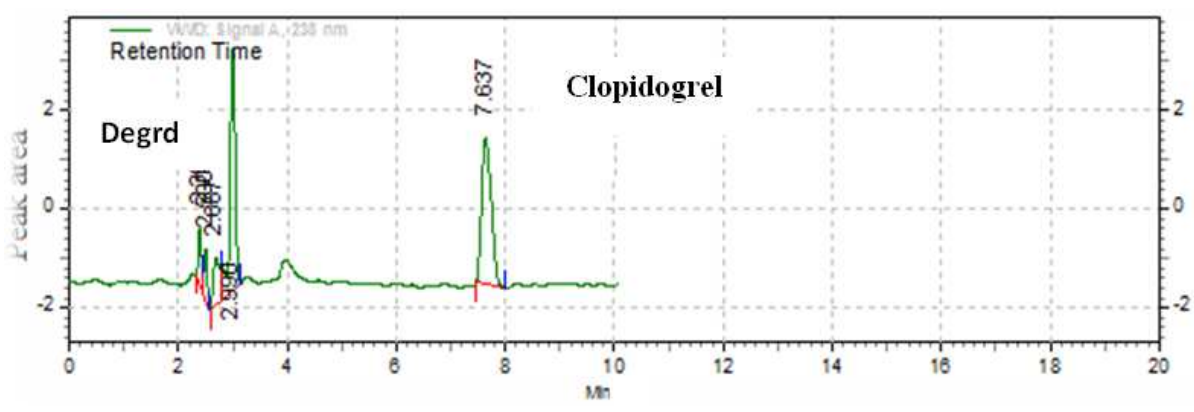

Degrd: degradation product peak at RT 2.99

Fig. 5: Chromatogram of acid-induced degradation of clopidogrel

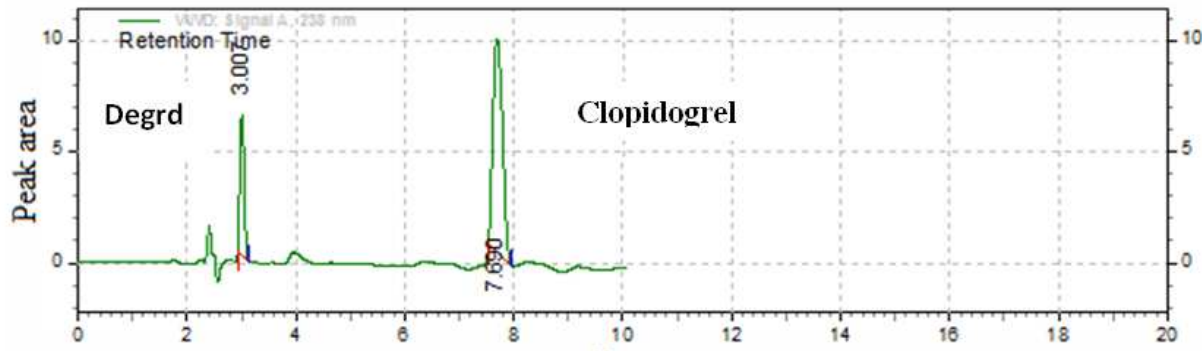

Degrd: degradation product peak at RT 3.00

Fig. 6: Chromatograms of base induced degradation of clopidogrel

Table 8: Summary of force degradation study for cilostazol and clopidogrel

\begin{tabular}{llllll}
\hline S. & Stress condition & Temperature and time & \multicolumn{2}{c}{ \% of degraded product } & \multicolumn{2}{c}{ Retention time of degraded peaks (min) } \\
\cline { 3 - 5 } No. & & & Cilostazol & Clopidogrel & Cilostazol \\
\hline 1. & Acid $(5 \mathrm{~N} \mathrm{HCl})$ & $80^{\circ} \mathrm{C}$ for $3 \mathrm{~h}$ & 28.57 & - & Clopidogrel \\
2. & Alkali $(0.1 \mathrm{~N} \mathrm{NaOH})$ & $80^{\circ} \mathrm{C}$ for $3 \mathrm{~h}$ & - & 25.30 & - \\
3. & Oxide $\left(20 \% \mathrm{H}_{2} \mathrm{O}_{2}\right)$ & $80^{\circ} \mathrm{C}$ for $3 \mathrm{~h}$ & 27.88 & - & 2.690 \\
\hline
\end{tabular}

Based on the report by Maruyama H. et al., a combination tablet dosage form containing cilostazol (100 mg) and clopidogrel (75 mg) were formulated by direct compression method. Microcrystalline cellulose compacts effectively and is the ideal choice for direct compression. Croscarmellose sodium serves as a super disintegrant with magnesium stearate and talc employed as lubricants. The powder blend exhibited good flow properties and could be directly compressed into tablets. The RP-HPLC method developed for the assay of the prepared tablet employing $0.025 \mathrm{M}$ phosphate buffer: acetonitrile: methanol $(20: 40: 40 \mathrm{v} / \mathrm{v} / \mathrm{v})$ as mobile phase on a C8 column, at a flow rate of $1.0 \mathrm{ml} / \mathrm{min}$ showed good peak shape, resolution and desired elution time. The method exhibited a good degree of accuracy and precision (\% recovery between 98-102\% with $\mathrm{RSD}<2 \%$ ) and is robust. The forced degradation study carried out under acid and base induced stress conditions for clopidogrel and under oxidative stress condition for cilostazol indicated that the standard drug peaks were well separated from their degradation product peaks. The proposed RP-HPLC method can thereby be useful to assess the stability of the tablet dosage from and is stability indicating. As there are no earlier reports on the formulation of this combination tablet dosage form, there are no methods available in the literature for their simultaneous analysis. Hence, this study will prove beneficial for the evaluation of tablet dosage from containing cilostazol and clopidogrel in combination. 


\section{CONCLUSION}

In the present study, attempts were made to formulate combined tablet dosage form containing cilostazol and clopidogrel which is recommended to be effective in the treatment of CVD as compared to monotherapy. Tablets were prepared by direct compression method and were evaluated. A new, simple, precise, robust, stabilityindicating HPLC method was developed for the first time for the simultaneous assay of cilostazol and clopidogrel in the prepared tablet formulation and validated as per ICH and USP guidelines. Under the optimized chromatographic conditions, it was possible to obtain separate peaks for the major degradation products of the two drugs well resolved from the standard peaks. This method can be employed for the analysis of solid dosage forms containing cilostazol and clopidogrel in combination. The method can also prove to be beneficial for assessment of the stability of the combined solid dosage form.

\section{ACKNOWLEDGEMENT}

The authors are thankful to the Principal, Dr. D. Y. Patil Institute of Pharmaceutical Sciences and Research, Pimpri, Pune for providing excellent facilities to carry out the work and Amsal Chem Pvt. Ltd. and Aarti Drugs Ltd. for providing gift samples of the drugs.

\section{CONFLICT OF INTERESTS}

Declared none

\section{REFERENCES}

1. Indian Pharmacopoeia, Government of India, Ministry of Health and Welfare, New Delhi; 2014.

2. British National Formulary. 68th ed. British Medical Association and Royal Pharmaceutical Society of Great Britain, London, September; 2014.

3. United State Pharmacopoeia. Asian ed. Rockville; 2013.

4. Maruyama H, Lakeda H, Dembo T, Nayoga H, Kato Y, Fukuoka T. Clopidogrel resistance and the effect of combination cilostazol in patients with ischemic stroke or carotid artery stenting using the verify now P2Y12 assay. Intern Med 2011:50:695-8.

5. Basniwal PK, Shrivastava PK, Jain D. Hydrolytic degradation profile and RP-HPLC estimation of cilostazol in tablet dosage form. Indian J Pharm Sci 2008;70:222.

6. Dharmendra D, Karan M, Bhoomi P, Rajshree CM. Quantification of cilostazol and telmisartan in combination using risk profile and uncertainty contour: a contemporary validation approach. J Chromatogr Sep-Tech 2015;6:1-8.

7. Sultana N, Ali KA, Arayne MS, Nawaz M. Simultaneous determination of clopidogrel and aspirin by RP-HPLC from bulk material and dosage formulations using multivariate calibration technique. J Chromatogr Sci 2011;49:165-9.

8. Kurien J, Jayasehar P. Stability indicating HPLC determination of Clopidogrel bisulfate in pharmaceutical dosage forms. Pharmacie Globale: Int J Chem Pharm 2013;4:1-5.

9. Dimple B, Vinodh M, Vinayak M. Development and validation of RP-HPLC method for the estimation of clopidogrel bisulphate. Malaysian J Anal Sci 2013;17:387-93.
10. Mounika A, Sriram N. Method development and validation of clopidogrel bisulphate by reverse phase-HPLC in bulk and pharmaceutical dosage forms. Int J Pharm Anal Res 2012;1:1-7.

11. Mashelkar UC, Renapurkar SD. A LC-MS compatible stabilityindicating HPLC assay method for Cefdinir. Int J Chem Tech Res 2010;2:114-21.

12. Bramer SL, Tata PN, Vengurlekar SS, Brisson JH. Method for the quantitative analysis of cilostazol and its metabolites in human plasma using LC/MS/MS. J Pharm Biomed Anal 2001;26:637-50.

13. Wang J, Wang Z, Chen C, Wang Z, Liu N, Ma J, et al. Gradient elution LC-ESI-MS determination of cilostazol in rat plasma and its application. Latt Am J Pharm 2012;31:240-4.

14. Sivarama KV, Ravi KD, Balamuralikrishna K, Rambabu C. Development and validation of a stability-indicating RP-HPLC method for the determination of clopidogrel bisulphate in bulk and its dosage form. Pharm Chem 2014;6:366-74.

15. Reddy DP, Swarnalatha D, Sidda RB, Karthik SKP, Sardar UM Design, development and characterization of the clopidogrel bisulfate transdermal drug delivery system. Asian J Pharm Clin Res 2015;8:277-80.

16. Singh S, Choudhary N, Rai J, Siddiqui I, Sharma S. A validated RP-UPLC method development for simultaneous estimation of lansoprazole and naproxen in bulk and tablet dosage form. Asian J Pharm Clin Res 2013;6:150-2.

17. Nagavi BJ, Gurupadayya B. Simultaneous estimation of clopidogrel and atorvastatin in human plasma using bioanalytical RP-Ultra fast liquid chromatographic method. Int J Chem Pharm Res 2015;7:30-5.

18. Gurupadayya BM, Nagavi JB. RP-UFLC method development and validation for simultaneous estimation of clopidogrel, pantoprazole, and rosuvastatin in human plasma: drug interaction studies. Int J Pharm Pharm Sci 2014;6:490-6.

19. Validation of analytical procedures, text, and methodology, ICH Harmonized Guidelines, Q2 (R1), Geneva; 2005. p. 1-13.

20. Text on Validation of Analytical Procedures. ICH, Harmonized Guidelines, Q2A, Geneva; 1994. p. 1-5.

21. Validation of Analytical Procedures: Methodology. ICH, Harmonized Guidelines, Q2B, Geneva; 1996. p. 1-8.

22. Kurien J, Jayasekhar P. Stability indicating HPLC determination of cilostazol in pharmaceutical dosage forms. Int J Pharm Bio Sci 2014;5:176-86.

23. Antic D, Filipi S, Agbaba D. A simple and sensitive TLC method for determination of clopidogrel and its impurity SR 26334 in pharmaceutical products. Acta Chromatogr 2007;18:199-206.

24. Housheh S, Trefi S, Haroun M, Chehna MF. A novel GC/MS, FTIR and NMR for the identification and characterization of clopidogrel bisulphate degradation products. Indian J Pharm Educ Res 2015;49:240-50.

\section{How to cite this article}

- $\quad$ Asha Thomas, Suraj Bhosale, Rabindra Nanda. Formulation of a solid dosage form containing clopidogrel and cilostazol and its HPLC analysis. Int J Pharm Pharm Sci 2017;9(6):12-18. 